\title{
DYNAMIC GAMES - AN EFFICIENT METHOD IN HANDBALL TRAINING
}

\author{
Cezar HANTĂU $\mathbf{1}^{*}$ \\ ${ }^{1}$ National University of Physical Education and Sport, Faculty of Physical Education and Sport, Bucharest, \\ Romania \\ *Corresponding author: hantau.cezar@gmail.com
}

https://doi.org/10.35189/dpeskj.2021.60.4.12

\begin{abstract}
The bodily experience of children who will be introduced to the handball game is reduced for many reasons whose enumeration does not find its place here. As a result, in order to increase their motor experience, it is necessary to use methods that, in addition to motor involvement, also determine an increased emotional involvement of children. Dynamic games, through their contents, forms and effects, have multiple formative and educational values, being recommended in sports training, especially during childhood. Starting from the child's spontaneity and pleasure to act and think, the psychomotor activity promotes a harmonious psychophysical development. Through playful pleasure, the child's motivation for movement, exploration and knowledge to pursue a significant and functional relationship with the environment (understood as space, object, movement, knowledge, relationship) is activated. In this paper, we want to show that the use of dynamic games, especially in the initial phase of handball training, has very good results in the learning of the main technical elements and particularly the increase of children's ability to apply them during the game. To demonstrate this, we chose two groups of beginners who participated in a one-year training programme. In the training of one group, we mainly used dynamic games, and in the training of the other one, we used classic handball training exercises.
\end{abstract}

Keywords: dynamic games, handball, technical elements.

\section{Introduction}

The way in which today's society acts on children's behaviour is easily observed in their motor behaviour. Thus, today's children have become very sedentary, and the childhood skills (running, jumping, climbing, throwing, etc.) are no longer found in their motor background. Because of this sedentary behaviour, according to the data provided by the World Health Organization (2021), over 39 million children under the age of 5 were overweight or obese in 2020. Physical inactivity is one of the major risk factors for mortality, contributing to increased overweight and obesity.

As a result of childhood sedentary lifestyle, the motor experience of children who will be introduced to the game of handball is reduced. In order to enrich their motor experience, it is necessary to use exercises that, in addition to motor involvement, also determine an increased emotional involvement of children. Therefore, movement games can be successfully used as training tools. This side of the game - the existence of a meaning - invigorates, on the one hand, the complex actions of players and, on the other hand, gives an emotional colour to the use of different technical procedures or tactical actions. Movement games, through their contents, forms and effects, have multiple formative and educational values, being recommended in sports training, especially during childhood. 
Many children and adolescents live their lives without physical activity due to the continuous pressure of parents to obtain very good results at school but also to children's lack of interest in physical activity (Sutherland et al., 2016). In recent decades, studies in the field of physical education have begun to highlight the limitations of traditional approaches to teaching based on traditional exercises (Bunker \& Thorpe, 1982). These limitations include insufficient consideration of the nature of movement games and an emphasis on the desire to achieve sports performance in the shortest possible time. All these things limit the success of students and cause their inability to solve problems that occur during games (Díaz-Cueto et al., 2010). To solve these problems, Bunker and Thorpe (1982) developed a model integrating tactics and technical skills into different movement games. This model proposes the use of movement games because they facilitate the overcoming of limitations by placing the learning of technical and tactical skills in a specific context, thus allowing the development of tactical thinking and knowledge, the improvement of skills in resolving situations and making decisions. The model created by Bunker and Thorpe (1982) is called Teaching Games for Understanding (TgfU) and uses different movement games to easily understand a certain sport. The design of this model is based on the idea that, in the physical education lesson or sports activities, especially for ages at which the initiation is made, time is mostly occupied with classic exercises for learning the technique and tactics and less with the game itself. As a result of this situation, the technique learned in such lessons or training sessions disappears when the game is played. So, the main idea is that, in order to easily approach the competitive game, we have to start with movement games (Figure 1).

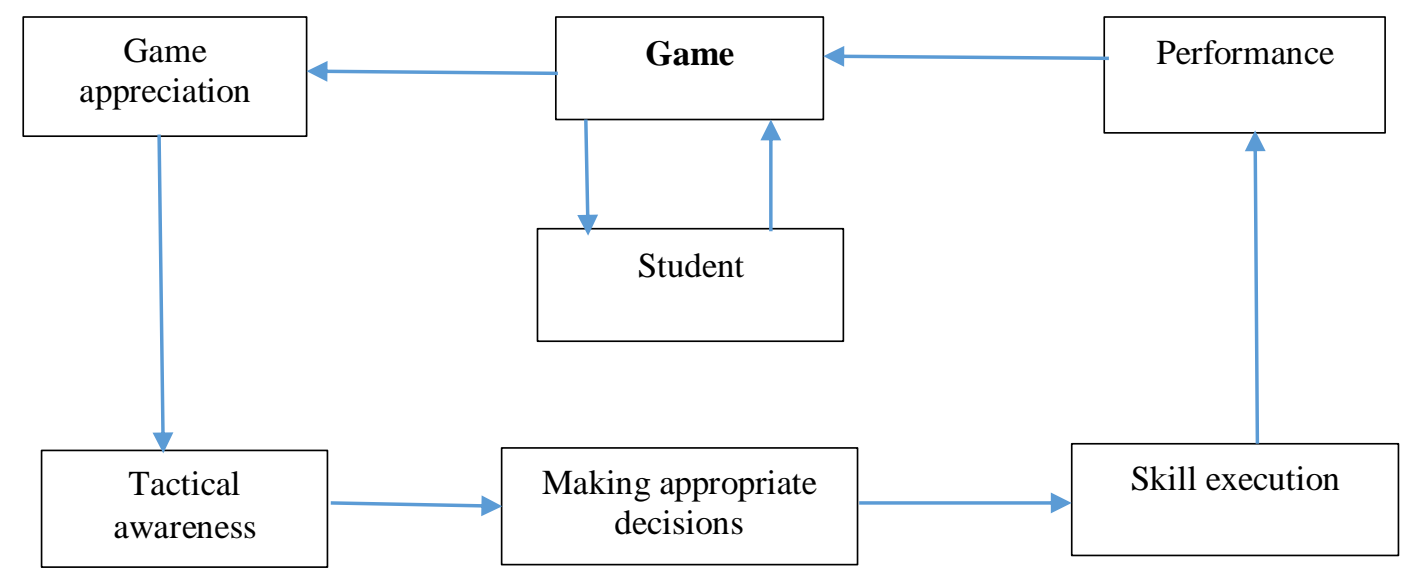

Figure 1. The learning model of sports games (Bunker \& Thorpe, 1982)

Since then, TgfU has attracted the attention of several researchers, teachers or coaches who have tried to improve this model. Chinese researchers Wang and Wang (2018) follow the same line, pointing out that training based on movement games is much more effective than training based on traditional exercises. Game-based learning is a method of using games while teaching a subject. The games used for this purpose were designed with the idea of obtaining learning outcomes; however, without supporting the student to understand the learning process, context and transferability, the value of game-based learning is lost (ColeyAgard, 2016). 
One of the main goals of physical education is to promote exercise and adopt a healthy lifestyle; to achieve this goal, physical education teachers approach the game-based teaching style to build the students' ability to apply the skills acquired in physical education lessons and develop their tactical knowledge (Dania et al., 2017).

Another advantage of game-based teaching is that students will be active in physical education lessons or training for more than half of their time. This is possible because, in the case of games, more students are simultaneously engaged in the activity than in the case of traditional exercises. This type of lesson or training leads to an increase in motor density during the activity as well as to an increase in exercise intensity. (Trost, 2004)

Blomqvist et al. (2005) conducted a research to assess the decision-making ability of high school students through a standardised video test. After this experiment, a correlation was found between decision-making ability and the correctness of technical execution.

If so far we have talked about physical education lessons, we would like to say a few words about sports training, which is also related to school physical activities such as school representative teams. Game-based training is a safe and effective way to improve fitness, which is comparable with or (in some cases) even superior to traditional methods. While traditional training provides a greater number of repetitions of technical skills, game-based training provides greater cognitive effort, an essential condition for increasing the ability to apply technical skills. Studies (Gabbett et al., 2009) investigating technical skill learning have shown that the use of games in training leads to greater improvements in technical skill learning and decision-making compared to traditional exercises used in sports training.

Another problem that occurs in physical activities is that of the differences between boys and girls. Previous studies (Gutierrez \& García-López, 2011) have shown that boys are much more active than girls and find greater pleasure in motor success compared to girls. They have also revealed that the use of an appropriate methodology can make disappear some of these differences, but their disappearance largely depends on the interactions that occur in the training process. These interactions can be successfully stimulated by using many games during training.

Similarly, the research conducted by Slingerland et al. (2014) highlights that the use of a teaching strategy based on grouping girls and boys in the same teams has produced very good results. Although girls' skills were lower compared to boys', it was observed that using mixed games in programmes over several weeks led to a significant increase in girls' skills. This teaching strategy had very good results, especially for girls in the age group 11-13 years. Even if this strategy can be used in primary school, its effects are not so significant because, at these ages, the differences between girls and boys are very small and often non-existent.

The physical education system does not always succeed in having a positive effect on all students. Most of the time, the exercises used in physical education or sports training classes cannot involve all participants emotionally. That is why some students tend to avoid these classes. Therefore, the use of games in physical education lessons can have positive effects on demotivated students and can create opportunities in making efforts with a beneficial effect on the health of these students. (Perlman, 2012)

Another study (Smith et al., 2015) conducted to see the level of student motivation for the physical education lesson was performed using two groups of students: one group was trained using traditional exercises, and the other group was trained based on games. The results 
showed increased levels of motivation, especially in girls, for the group trained on the basis of games. However, there may be a flip side of the coin: if the period of applying movement games exceeds 12 weeks, there is a possibility of decreasing the level of motivation.

Another study (Fairclough, 2006) was conducted to measure physical activity, skill levels and the pleasure that boys and girls feel during physical activity. The results of this research showed that the pleasure and manifestation of skills was different between girls and boys, in the sense that boys had higher levels of skills. At high exercise intensities, girls did not have the same pleasure to continue the activity. However, the level of pleasure in both girls and boys was increased when physical activities took the form of games.

As a conclusion of this part, we can mention that, for the formation of specific skills, video games were also successfully used but their potential is not fully exploited. The results obtained in various research studies (Hilliard et al., 2016) have shown that games focused on moral learning can lead to a great deal of involvement on the part of children.

\section{Research purpose}

The main purpose of this research is to update the model created by Bunker and Thorpe (1982), and secondarily, to compare the ways of expression during the game play of two groups of children who followed the same training programme but used different types of exercises. As a result of this research, we want to emphasise the importance of using movement games in teaching children, especially in the early stages of learning the game of handball.

\section{Research hypothesis}

The use of movement games in children's training determines a better application of the knowledge acquired during the game than the use of analytical training exercises.

\section{Methodology}

\section{Participants}

The research was conducted on two groups of 15 children aged 8 years, boys practising mini-handball for two years. The differences between these groups consisted in the way they were trained. Group A was trained on the basis of movement games, and Group B was trained using analytical exercises. Both groups were trained according to the same programme, only the exercises used were different.

The third year of training coincides with the transition to the second round of training in the first stage. This round is called a "guided general training round". It is a stage of general training because the aim is to strengthen technical elements in their general form and develop general motor skills. "Directed" comes from the fact that the entire training is oriented towards the evolution of children in conditions of adversity. Actually, in this stage, bilateral games also appear in the company of unknown opponents, and the main objective of this stage is "getting used to the opponent". Regarding the training programme, three training 
sessions per week with a duration of 75 minutes are scheduled in this stage and, at the end of each training stage, participation in a friendly tournament is scheduled, which involves competing in at least four friendly games. The purpose of the tournaments planned at the end of the preparation stages is to check the level of training instead of achieving sports performance.

From the point of view of training in the third year of preparation, the aims pursued are:

- technical preparation - strengthening the technical elements acquired so far (moving on the field, dribbling, holding and handling the ball, catching and passing the ball in a stationary position and while moving and throwing on goal from ground support and running); in addition, the following technical elements will be introduced to be learned: attacking the opponent in possession of the ball and throwing on goal while jumping;

- tactical preparation - as a new training factor - learning to mark and demarcate;

- physical preparation - continues with the education of coordination skills and the development of speed, with an emphasis on the speed of movement; strength will be developed in its general form, the emphasis being on the development of muscle groups of the abdomen, back and lower limbs; endurance will be developed in its general form, with an emphasis on aerobic capacity;

- psychological preparation - will be oriented towards educating sensory skills, neuro- and psychomotor skills, social behaviour, the spirit of competition, and building the team spirit;

- theoretical preparation - another new training component that appears in this stage is focused on acquiring the basic notions of the regulation (playing the ball, the behaviour towards the opponent, etc.). (Hantău, 2017)

\section{Research methods}

This applied research uses general methods (literature review), investigative methods (observation and experiment) as well as analysis and interpretation methods (mathematical statistics and graphical method). From an experimental point of view, the dependent variable in our case is the behaviour of children during the game after a period of training, and the independent variable is represented by the exercises used for their training.

\section{Procedure}

The research was carried out with two mini-handball teams: group A (Middle School no. 80, Bucharest) and group B (Middle School no. 81, Bucharest). The training of group A was based on the use of movement games, and the training of group B was based on the use of classic, analytical exercises to learn the technique and tactics.

The experiment began with the participation in a mini-handball tournament where each group played four games, which represented the initial test. This tournament was followed by a period of eight months during which training exercises in the form of movement games were applied to group A, while analytical training exercises were applied to group B. At the end of this period, both groups participated in the second tournament where they played another four games, which represented the final test. (Tables 1 and 2) 
Table 1. Weekly schedule for group A

\begin{tabular}{cccc}
\hline DAY & MONDAY & WEDNESDAY & FRIDAY \\
\hline Hour & $12.00-13.15$ & $12.00-13.15$ & $12.00-13.15$ \\
\hline
\end{tabular}

The data obtained after observing the games played in the two tournaments were based on video analysis performed with ORTEC Sports software for analysis and interpretation. With the help of this video analysis method, we tracked the following aspects: number of goals, number of shots, number of offensive duels won, number of defensive duels won, number of ball interceptions, number of passes and duration of attacks. All these elements were counted, collected and averaged per game. To compare the results, each item was assigned points (p). Positive actions were: ball actions ( $1 \mathrm{p})$, shots on goal ( $1 \mathrm{p})$, scored goals $(3 \mathrm{p})$, passes ( $1 \mathrm{p})$, forward passes ( $1 \mathrm{p})$, offensive duels won ( $3 \mathrm{p})$, defensive duels won ( $2 \mathrm{p})$, ball interceptions ( $2 \mathrm{p})$, attack duration 0-5 sec ( $3 \mathrm{p})$, attack duration 5-15 sec (6 p). The application of movement games during the eight months of training followed a certain pattern.

Thus, the technical elements that need to be strengthened are introduced in movement games where the opponent appears and thus an attempt is made to develop the players' ability to apply them during the game. The new technical elements and actions that need to be learned are introduced for the first time in simple movement games that form that skill. When we consider that the skill is formed, it is introduced in movement games with the opponent to build the ability to apply it in the game. When we notice that the ability to apply it in the game has been created, movement games will be applied to build the ability to make appropriate decisions. An example for ball throwing:

Learning skills

Throwing over the line (variants: at a distance, in circles, etc.)

Keep the ground clean

Throwing at a fixed target

Application - ability building

Dribbling and throwing at a fixed target

Throwing at a mobile target

Understanding, appropriate decision-making and application

Defending the fortress

Table 2. Training planning for group A

\begin{tabular}{|c|c|c|c|c|c|c|c|}
\hline Month & $\mathrm{Nc}$ & Dec. & Jan. & March & April & June & \multirow[t]{3}{*}{ Total } \\
\hline Week & \multicolumn{2}{|r|}{$1-7$} & \multicolumn{3}{|c|}{$8-18$} & $19-29$ & \\
\hline Stage & & $\mathrm{I}$ & & II & & III & \\
\hline $\begin{array}{l}\text { Number of training } \\
\text { sessions }\end{array}$ & 17 & $\begin{array}{l}\text { Strengthening } \\
\text { technical elements }\end{array}$ & 32 & $\begin{array}{l}\text { Strengthening } \\
\text { technical elements }\end{array}$ & 32 & $\begin{array}{l}\text { Strengthening technical } \\
\text { elements (dribbling, }\end{array}$ & 81 \\
\hline Physical prep. (h) & 8.5 & (dribbling, catching, & 16 & (dribbling, catching, & 16 & catching, throwing on goal) & 40.5 \\
\hline Technical prep. (h) & 8.5 & throwing on goal) & 16 & throwing on goal) & 16 & Initiating feints and changes & 40.5 \\
\hline Psychological prep. (h) & 1 & Initiating the attack & 2 & Initiating the attack & 2 & of direction & 5 \\
\hline Tactical prep. (h) & 2.12 & of the opponent in & 4 & of the opponent in & 4 & Strengthening the attack of & 10.12 \\
\hline Theoretical prep. (h) & 1 & possession of the & 2 & possession of the & 2 & the opponent in possession & 5 \\
\hline Evaluation (h) & 3 & ball & 0 & ball & 3 & of the ball & 6 \\
\hline Competition (h) & 3 & Initiating marking- & 0 & Initiating marking- & 3 & Strengthening marking- & 6 \\
\hline Number of games & 4 & $\begin{array}{l}\text { demarcation } \\
\text { Introducing the } \\
\text { mini-handball game }\end{array}$ & 0 & $\begin{array}{l}\text { demarcation } \\
\text { Introducing the } \\
\text { mini-handball game }\end{array}$ & 4 & $\begin{array}{l}\text { demarcation } \\
\text { Consolidating the mini- } \\
\text { handball game }\end{array}$ & 8 \\
\hline
\end{tabular}




\section{Results}

Table 3. Results for group A

\begin{tabular}{llcccc}
\hline \multirow{2}{*}{ No. } & Technical and tactical actions & \multicolumn{2}{c}{$\begin{array}{c}\text { Number of technical and } \\
\text { tactical actions }\end{array}$} & \multicolumn{2}{c}{$\begin{array}{c}\text { Transforming actions into } \\
\text { points }\end{array}$} \\
\cline { 3 - 5 } & & Initial test & Final test & Initial test & Final test \\
\hline 1 & ball actions & 267 & 310 & 267 & 310 \\
2 & shots on goal & 26 & 42 & 26 & 42 \\
3 & scored goals & 10 & 32 & 30 & 96 \\
4 & Passes & 109 & 182 & 109 & 182 \\
5 & forward passes & 68 & 99 & 68 & 99 \\
6 & offensive duels won & 35 & 64 & 105 & 192 \\
7 & defensive duels won & 43 & 66 & 86 & 132 \\
8 & ball interceptions & 18 & 44 & 36 & 88 \\
9 & attack duration 0-5 sec & 26 & 37 & 78 & 111 \\
10 & attack duration 5-15 sec & 25 & 41 & 150 & 246 \\
& $\quad$ Mean & & & $\mathbf{9 5}$ & $\mathbf{1 4 9 . 8}$ \\
\hline
\end{tabular}

Applying the Student t-Test to the results obtained by group A (Table 3) following the recordings made in the two tournaments, it is observed that the scores achieved in the second test are not accidental, which is confirmed by the calculated t-value -6.67 ( $p<0.05)$. Therefore, we can say that the difference between the initial test and the final test is statistically significant, meaning that the progress made between the two tests is due to the training method that was applied. We also calculated the effect size index (Cohen's d). For group A, Cohen's $\mathrm{d}=1.49$ which translates into a very strong effect of the training intervention on the results obtained.

Table 4. Results for group B

\begin{tabular}{llcccc}
\hline \multirow{2}{*}{\begin{tabular}{c} 
No. \\
\cline { 2 - 5 }
\end{tabular}} & $\begin{array}{c}\text { Technical and tactical } \\
\text { actions }\end{array}$ & \multicolumn{2}{c}{$\begin{array}{c}\text { Number of technical and } \\
\text { tactical actions }\end{array}$} & \multicolumn{2}{c}{$\begin{array}{c}\text { Transforming actions into } \\
\text { points }\end{array}$} \\
\cline { 3 - 6 } & & Initial test & Final test & Initial test & Final test \\
\hline 1 & ball actions & 258 & 269 & 258 & 269 \\
2 & shots on goal & 27 & 27 & 27 & 27 \\
3 & scored goals & 11 & 12 & 33 & 36 \\
4 & passes & 111 & 115 & 111 & 115 \\
5 & forward passes & 66 & 59 & 66 & 59 \\
6 & offensive duels won & 33 & 35 & 99 & 105 \\
7 & defensive duels won & 45 & 41 & 90 & 82 \\
8 & ball interceptions & 17 & 16 & 34 & 32 \\
9 & attack duration 0-5 sec & 25 & 19 & 75 & 57 \\
10 & attack duration 5-15 sec & 31 & 28 & 186 & 168 \\
& $\quad$ Mean & & & $\mathbf{9 7 . 9}$ & $\mathbf{9 5}$ \\
& Standard deviation & & & $\mathbf{7 3 . 4 0}$ & $\mathbf{7 5 . 3 4}$ \\
\hline
\end{tabular}

Applying the Student t-Test to the results obtained by group B (Table 4) following the recordings made in the two tournaments, we notice that the difference achieved is not significant $(\mathrm{p}>0.05)$ - the calculated t-value 0.936 is smaller than its critical value (2.26). Thus, we can say that the results obtained by group B in the final test are not significantly increased due to the training method $(\mathrm{p}=0.373)$. 
Next, we will make a comparison between the results of the two groups in the tests performed.

\section{Comparison of group A with group B}

The data obtained show that there are differences between group A and group B. In general, the values obtained by group A are higher than the values obtained by group B. However, the question arises whether these differences are due to the different training of the two groups.

To compare the results obtained in both tests by the two groups, the Mann-Whitney test (U test) for two independent samples was used.

The results obtained in the initial test are as follows:

- the $U$-value is 50 . The critical value of $U$ at $p<0.05$ is 23 . Therefore, the result is not significant at $p<0.05$.

- the $z$-score is 0.037 , the $p$-value is 0.96 - the result is not significant at $p<0.05$.

The results obtained in the final test are as follows:

- the $U$-value is 27 . The critical value of $U$ at $p<0.05$ is 23 . Therefore, the result is not significant at $p<0.05$.

- $\quad$ the $z$-score is 1.70 , the $p$-value is 0.089 - the result is not significant at $p<0.05$.

In the final test, even if there are not statistically significant differences between the two investigated groups, namely group A - trained on the basis of movement games (median = 121.5) and group B - trained on the basis of analytical exercises (median $=70.5$ ), we can observe that the alpha significance threshold has been greatly reduced (comparing to the initial test), being relatively close to 0.05 . After calculating these values, we can say that the differences between the two groups in the final test are very important and are due to the programmes applied between the two tests.

Based on the sequence of movement-game types and the fact that the differences between the two groups are very important, we can change the Teaching Games for Understanding (TgfU) model into Teaching Games for Understanding and Application (TgfUaA).

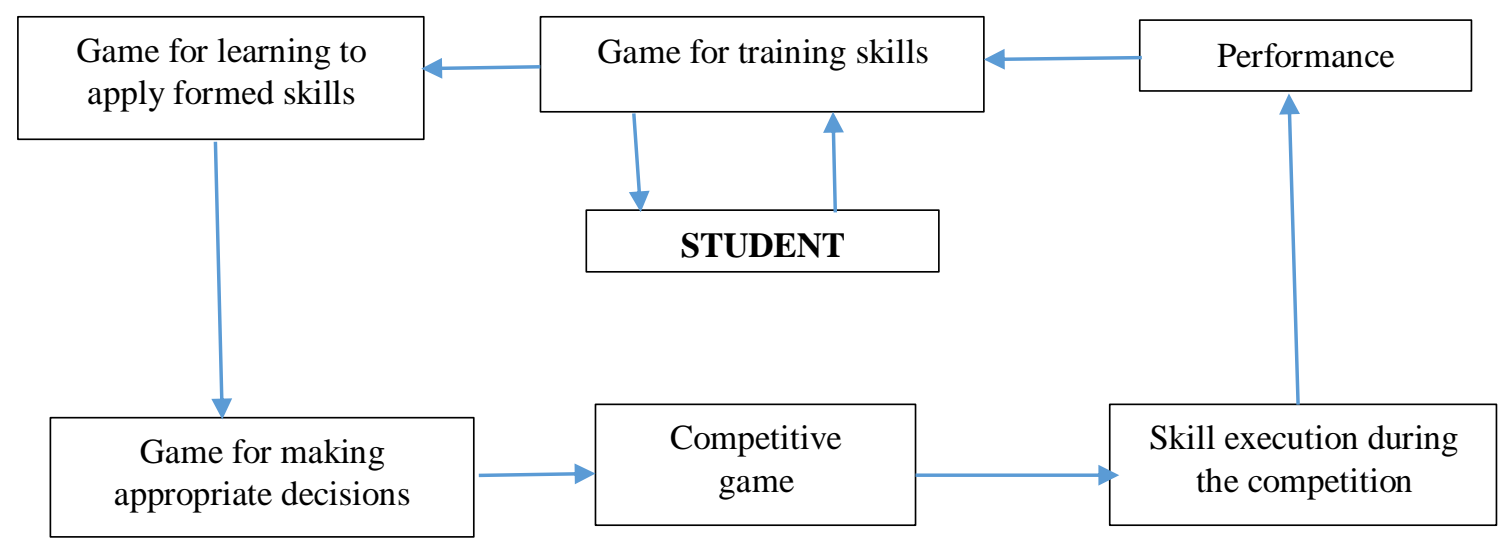

Figure 2. Teaching Games for Understanding and Application (TgfUaA): A model for movement games 


\section{Conclusion}

The experience gained in 27 years of coaching has shown us that all athletes, regardless of age, participate with much more involvement in workouts where movement games are used as training exercises. These types of means manage to encompass all the factors of training at the same time, but more importantly, the emotional participation of athletes is incomparably higher than in the case of analytical exercises for learning-strengthening-improving specific skills. This is especially true for children. Knowing that excitation processes are more active than inhibition processes at young ages, children's attention is very difficult to capture. The role of movement games, in addition to the advantages listed above, is to capture children's attention and make them actively participate in these activities.

Another conclusion that emerges from this research is that athletes trained on movement games have a greater ability to apply formed skills during the game compared to children trained on analytical exercises, and this is more prominent at a young age.

Finally, we can say that the research hypothesis according to which "the use of movement games in children's training determines a better application of the knowledge acquired during the game than the use of analytical training exercises" has been confirmed.

\section{References}

Blomqvist, M., Vanttinen, T., \& Luhtanen, P. (2005). Assessment of secondary school students' decision-making and game-play ability in soccer. Physical Education and Sport Pedagogy, 10(2), 107-119. https://doi.org/10.1080/17408980500104992

Bunker, D., \& Thorpe, R. (1982). A model for the teaching of games in the secondary school. Bulletin of Physical Education, 18(1), 5-8.

Coley-Agard, N. (2016). Game-based \& interactive learning. Activities for early years. Ministry of Education, Youth and Information, Kingston, Jamaica.

Dania, A., Kossyva, I., \& Zounhia, K. (2017). Effects of a Teaching Games for Understanding program on primary school students' physical activity patterns. European Journal of Physical Education and Sport Science, 3(2), 81-93. https://doi.org/10.46827/EJPE.V0I0.592

Díaz-Cueto, M., Hernández-Álvarez, J. L., \& Castejón, F. J. (2010). Teaching Games for Understanding to in-service physical education teachers: Rewards and barriers regarding the changing model of teaching sport. Journal of Teaching in Physical Education, 29(4), 378-398. https://doi.org/10.1123/jtpe.29.4.378

Fairclough, S. (2006). Physical activity, perceived competence and enjoyment during high school physical education. Physical Education \& Sport Pedagogy, 8(1), 5-18. https://doi.org/10.1080/1740898030080102

Gabbett, T., Jenkins, D., \& Abernethy, B. (2009). Game-based training for improving skill and physical fitness in team sport athletes. International Journal of Sports Science \& Coaching, 4(2), 273-283. https://doi.org/10.1260/174795409788549553

Gutierrez, D., \& García-López, L. M. (2012). Gender differences in game behaviour in invasion games. Physical Education and Sport Pedagogy, 17(3), 289-301. https://doi.org/10.1080/17408989.2012.690379

Hantău, C. (2017). Minihandbal - stadiul I al instruirii în handbal [Mini-handball - $1^{\text {st }}$ stage of handball training]. Printech. 
Hilliard, L. J., Buckingham, M. H., Geldhof, G. J., Stack, C., Gelgoot, E. S., Bers, M., \& Lerner, R. (2016). Perspective taking and decision-making in educational game play: A mixed-methods study. Applied Developmental Science, 22(1), 1-13. http://dx.doi.org/10.1080/10888691.2016.1204918

Perlman, D. (2012). The influence of the Sport Education Model on a motivated students' inclass physical activity. European Physical Education Review, 18(3), 335-345. https://doi.org/10.1177/1356336X12450795

Slingerland, M., Haerens, L., Cardon, G., \& Borghouts, L. (2014). Differences in perceived competence and physical activity levels during single-gender modified basketball game play in middle school physical education. European Physical Education Review, 20(1), 20-35. https://doi.org/10.1177/1356336X13496000

Smith, L., Harvey, S., Savory, L., Fairclough, S., Kozub, S., \& Kerr, C. (2015). Physical activity levels and motivational responses of boys and girls: A comparison of direct instruction and tactical games models of games teaching in physical education. European Physical Education Review, 21(1), 93-113. https://doi.org/10.1177/1356336X14555293

Sutherland, R., Campbell, E., Lubans, D. R., Morgan, P. J., Okely, A. D., Nathan, N., Gillham, K., Lecathelinais, C., \& Wiggers, J. (2016). Physical education in secondary schools located in low-income communities. Physical activity, levels, lessons, content and teacher interaction. Journal of Science and Medicine in Sport, 19(2), 135-141. https://doi.org/10.1016/j.jsams.2014.12.003

Trost, S. G. (2004). School physical education in the post-report era: An analysis from Public Health. Journal of Teaching in Physical Education, 23(4), 318-337. https://doi.org/10.1123/jtpe.23.4.318

Wang, M., \& Wang, L. (2018). Teaching Games for Understanding intervention to promote physical activity among secondary school students. BioMed Research International, 2018: 3737595. https://doi.org/10.1155/2018/3737595

World Health Organization. (2021). Obesity and overweight. http://www.who.int/mediacentre/factsheets/fs311/en/ 